\title{
The Roles of Climate, Phylogenetic Relatedness, Introduction Effort, and Reproductive Traits in the Establishment of Non-Native Reptiles and Amphibians
}

\author{
NICOLA J. VAN WILGEN*† AND DAVID M. RICHARDSON* \\ ${ }^{*}$ Centre for Invasion Biology, Department of Botany \& Zoology, Stellenbosch University, Private Bag X1, Matieland 7602, \\ South Africa \\ †Cape Research Centre, South African National Parks Scientific Services, P.O. Box 216, Steenberg 7947, South Africa, \\ email nvanwilgen@gmail.com or nicola.vanwilgen@sanparks.org
}

\begin{abstract}
We developed a method to predict the potential of non-native reptiles and amphibians (berpetofauna) to establish populations. This method may inform efforts to prevent the introduction of invasive non-native species. We used boosted regression trees to determine whether nine variables influence establishment success of introduced berpetofauna in California and Florida. We used an independent data set to assess model performance. Propagule pressure was the variable most strongly associated with establishment success. Species with short juvenile periods and species with phylogenetically more distant relatives in regional biotas were more likely to establish than species that start breeding later and those that have close relatives. Average climate match (the similarity of climate between native and non-native range) and life form were also important. Frogs and lizards were the taxonomic groups most likely to establish, whereas a much lower proportion of snakes and turtles established. We used results from our best model to compile a spreadsheet-based model for easy use and interpretation. Probability scores obtained from the spreadsheet model were strongly correlated with establishment success as were probabilities predicted for independent data by the boosted regression tree model. However, the error rate for predictions made with independent data was much higher than with cross validation using training data. This difference in predictive power does not preclude use of the model to assess the probability of establishment of herpetofauna because (1) the independent data had no information for two variables (meaning the full predictive capacity of the model could not be realized) and (2) the model structure is consistent with the recent literature on the primary determinants of establishment success for berpetofauna. It may still be difficult to predict the establishment probability of poorly studied taxa, but it is clear that non-native species (especially lizards and frogs) that mature early and come from environments similar to that of the introduction region have the bighest probability of establishment.
\end{abstract}

Keywords: biological invasions, exotic species, herpetofauna, prediction, risk assessment

El Papel del Clima, la Relación Filogenética, el Esfuerzo de Introducción y las Características Reproductivas en el Establecimiento de Reptiles y Anfibios No Nativos

Resumen: Desarrollamos un método para predecir el potencial de reptiles y anfibios no nativos (herpetofauna) para establecer poblaciones. Este método puede proporcionar información para los esfuerzos de prevención de la introducción de especies no nativas invasoras. Utilizamos árboles de regresión y técnicas de remuestreo para determinar si nueve variables influyen en el establecimiento exitoso de berpetofauna introducida en California y Florida. Utilizamos un conjunto de datos independientes para evaluar el funcionamiento del modelo. Las especies con períodos juveniles cortos y especies con parientes más distantes filogenéticamente en las biotas regionales tuvieron mayor probabilidad de establecimiento que las especies 
que tardan en reproducirse. La concordancia climática promedio (la similitud en el clima entre el rango de distribución nativo y el no nativo) y la forma de vida también fueron importantes. Las ranas y lagartijas fueron los grupos taxonómicos con mayor probabilidad de establecimiento, mientras que serpientes y tortugas lo bicieron en mucho menor proporción. Utilizamos los resultados de nuestro mejor modelo para compilar un modelo basado en boja de cálculo para facilitar su uso y la interpretación. Los valores de probabilidad obtenidos del modelo de boja de cálculo se correlacionaron estrechamente con el éxito de establecimiento, del mismo modo que las probabilidades obtenidas de los árboles de regresión y técnicas de remuestreo basados en datos independientes. Sin embargo, la tasa de error para las predicciones a partir de datos independientes fue mucho más alta que con la validación cruzada. Esta diferencia en el poder predictivo no impide el uso del modelo para evaluar la probabilidad de establecimiento de berpetofauna porque los datos independientes no tenían información para dos variables (lo que significa que no se podía alcanzar la capacidad predictiva total del modelo) y que la estructura del modelo es consistente con la literatura reciente sobre los determinantes primarios del éxito de establecimiento de berpetofauna. Puede que aun sea difícil predecir la probabilidad del éxito de establecimiento de taxa poco estudiados, pero es claro que las especies no nativas (especialmente lagartijas y ranas) que maduran jóvenes y provienen de ambientes similares a los de la región de introducción tienen la mayor probabilidad de establecimiento.

Palabras Clave: especies exóticas, evaluación de riesgo, invasiones biológicas, herpetofauna, predicción

\section{Introduction}

Because reptiles and amphibians (herpetofauna) have been (Kraus 2009) and continue to be (Auliya 2003; van Wilgen et al. 2010) popular pets and because many species are transported accidentally in ship cargo and with nursery plants, herpetofauna are being moved around the world at an increasing rate (Kraus 2003, 2009). Although invasions of non-native herpetofauna are currently of less concern than invasions of some other taxonomic groups (e.g., plants), the massive increase in the trade of herpetofauna is increasing the probability of their establishment. Effects of biological invasions range from effects on single species to ecosystem-level effects and effects on the evolution of other species (Mack et al. 2000; Grosholz 2002; Bomford et al. 2005). Non-native species (sensu Richardson et al. 2011) may also affect trade and agriculture (Beard \& Pitt 2005) and may therefore have large economic effects. Although regulations addressing the introduction and dissemination of nonnative organisms are in place in many countries, better protocols are needed to prevent establishment of these species (Hulme 2011).

Risk assessment includes evaluation of both the probability of an event occurring and the magnitude of its effects (Andersen et al. 2004; Burgman 2005). Risk assessment for non-native invasive species includes estimating the probability of arrival, establishment, and spread of the species and the potential effects of a species establishing. For a non-native species to have an effect, the species must overcome a series of transport, environmental, and biotic barriers (Richardson et al. 2000). We sought to develop a model that predicts how likely a species is to overcome these barriers and establish viable populations. If accurate, such a model could provide an objective and transparent way to assess the probability of a non-native species becoming established. In this assessment we modeled only the probability of establishment and not potential effects of species establishing, but by combining this probability with an assessment of potential biological, social, and economic effects, the level of risk associated with the introduction can be estimated.

Previous assessments of the establishment potential of non-native vertebrates have included examination of the similarity of climate between the native and nonnative range (i.e., climate match), propagule pressure (Simberloff 2009), life-history characteristics, and evidence of past invasion success (Bomford 2003; Forsyth et al. 2004; Bomford et al. 2009). Methods for assessment of non-native herpetofauna are still at an early stage of development. Bomford et al. (2005, 2009) propose assessing the probability of establishment on the basis of taxonomic group, history of invasion elsewhere, and climate match. However, many other factors may determine probability of establishment for herpetofauna, including life-history traits (e.g., reproductive output) and biotic factors inherent to the system of introduction (e.g., presence of potential predators; Meshaka et al. 2004). Ideally, these factors should also be considered in risk assessments, though data are scarce for most species.

Fujisaki et al. (2010) proposed a series of models that do use life-history factors to assess the probability of establishment of reptiles in southern Florida. Here, we added to their models previously unassessed phylogenetic variables and used boosted regression trees (BRTs) to determine which factors were most strongly linked to the establishment success of non-native reptiles and amphibians introduced to California and Florida. We then used independent data (introductions to Hawaii, Japan, and Great Britain) to evaluate the predictive performance of the BRT models. Finally, we adapted the BRT model results into a simpler model that can be used to screen the establishment potential of herpetofauna. 


\section{Methods}

\section{Species}

The United States has the highest known number of introductions of non-native reptile and amphibian species of any country (Kraus 2009). We selected 96 species introduced to Florida and 62 introduced to California to build a model of establishment success. Of these species, 118 were reptiles (16 of which were introduced to both states) and 21 were amphibians ( 3 introduced to both states). Most species were introduced via the pet trade or in ship cargo (Meshaka et al. 2004; Kraus 2009). On the basis of the literature (notably Kraus 2009) and after consultation with experts from the United States, we assigned species to one of two groups on the basis of their establishment success: failed (including species whose populations died out) and established (species for which breeding populations persist).

\section{Selection of Predictor Variables}

Although the potential of individual species to invade or spread has been evaluated (e.g., Ficetola et al. 2009; Rodda et al. 2009; Rödder 2009), few attempts have been made to identify variables that universally affect the probability of establishment of non-native reptiles or amphibians (Reed 2005; Bomford et al. 2009; Fujisaki et al. 2010). In addition, some of the factors considered by other researchers (e.g., previous history of establishment, taxonomic group, and "manageability" [Bomford et al. 2009; Fujisaki et al. 2010]) are surrogates for a series of more complex trade-related, physiological, and biological characteristics that are likely to vary among regions, which makes them difficult to apply universally.

On the basis of previous studies, we chose nine predictor variables (Table 1), including two that have not been evaluated previously. We calculated climate match with generalized additive models (van Wilgen et al. 2009) on the basis of distribution data from WildFinder (WWF-US [World Wildlife Fund-United States] 2006). We used the maximum and the mean climatic suitability across the area of the assessment as candidate predictors for our model. We also used two phylogenetic variables derived from a reptile phylogeny, which included native and introduced non-native species (van Wilgen \& Richardson 2011): mean phylogenetic distance (AV), which indicated the average genetic distance (including branch length) between an introduced species and all native species in the region of introduction; and nearest neighbor distance (NN) calculated as the genetic distance between an introduced species and its closest native relative. We did not, however, have a comparable phylogeny for amphibians and therefore had no comparable phylogenetic information for this group. The full data set is provided in the Supporting Information.

\section{Model Selection and Validation}

Because species were categorized as established (1) or failed (0), establishment success was represented as a Bernoulli distribution. We modeled the probability of establishment success with BRTs in $\mathrm{R}$ (version 2.13.0, $\mathrm{R}$ Development Core Team 2011) (library gbm [Ridgeway 2007] with additional functions written by J. Elith and J.R. Leathwick [appendix S3, supporting information of Elith et al. (2008)]. Boosted regression trees combine two statistical methods: regression trees and boosting. Regression trees describe the dependent variable through a series of binary splits in the value of predictor variables that can be visualized by a physical 'if this, then that' decision tree. Boosting is a process by which the fit of a model to data is improved by the addition of iterations (trees)

Table 1. Variables used in the boosted regression tree model of non-native herpetofauna establishment probability.

\begin{tabular}{|c|c|c|}
\hline $\begin{array}{l}\text { Average phylogenetic distance to all native relatives } \\
\text { (reptiles only), calculated from a molecular phylogeny }\end{array}$ & AV & van Wilgen \& Richardson 2011 \\
\hline Number of clutches or reproductive events per year & RY & $\begin{array}{l}\text { published works, internet databases, } \\
\text { encyclopedias }\end{array}$ \\
\hline $\begin{array}{l}\text { Life form (used here as a surrogate for order or super } \\
\text { order) crocodile }=1, \text { lizard }=2, \text { snake }=3 \text {, turtle }=4 \text {, } \\
\text { salamander }=5, \text { frog }=6\end{array}$ & $\mathrm{LF}$ & Kraus 2009 \\
\hline Age at sexual maturity (months) & $\mathrm{AM}$ & $\begin{array}{l}\text { published works, internet databases, } \\
\text { encyclopedias }\end{array}$ \\
\hline Average clutch size & $\mathrm{CS}$ & $\begin{array}{l}\text { published works, internet databases, } \\
\text { encyclopedias }\end{array}$ \\
\hline
\end{tabular}


that concentrate on the cases that were poorly fit in previous iterations (trees) (Leathwick et al. 2006). Although many other types of models can only be built with complete data sets, BRTs allow for the inclusion of variables for which data are missing (Elith et al. 2008). Boosted regression trees also fit nonlinear relations and automatically account for interactions between predictors. Furthermore, BRTs allow for the inclusion of untransformed continuous and categorical variables (Elith et al. 2008).

J. Elith and J.R. Leathwick's functions (appendix S3 [supporting information] in Elith et al. [2008]) allow one to determine the optimal number of trees to include in a model by varying the learning rate, which determines the extent to which individual trees contribute to the model, and the tree complexity, which controls the number of interactions in the model. Additionally, the "bag fraction" (i.e., the degree to which randomness is introduced into the model to avoid overfitting) can be set. We varied these three parameters and compared the predictive performance of resultant models. We then set learning rate to 0.001 , tree complexity to 5 , and the bag fraction to 0.5 for the final model.

We used the function gbm.step (appendix S3 [supporting information] in Elith et al. [2008]) to incorporate cross-validation into the model-selection process and determination of the optimal number of trees. A random subset of $10 \%$ of the data was withheld at each step, and the remaining data (training data) were used to build the model. We repeated this process with the 10 mutually exclusive sets of training data and used the withheld data to evaluate model performance (further details are given in Elith et al. [2008]). We used three measures to evaluate and describe the model performance. We evaluated the area under the curve of the receiver operating characteristic (ROC) estimated during cross-validation (Hanley \& McNeil 1982). We used explained deviance to evaluate the overall performance of each model (Yee \& Mitchell 1991; Ferrier \& Watson 1997). We calculated the percentage of deviance explained by competing models as (null deviance-residual deviance)/null deviance $\times 100$, which is analogous to $R^{2}$ in regression models. We obtained the null and residual deviance values from the self.statistics in the gbm.step output. To assess the discriminative power of the model, we compared the probabilities fit by the model for failed and established species with actual establishment success by means of a nonparametric Mann-Whitney test (Ferrier \& Watson 1997) in R (version 2.13.0, R Development Core Team 2011).

We used an independent data set of species introduced to Hawaii, Japan, and Great Britain as an additional evaluation of model performance (Kraus 2009). We researched data on the variables described in Table 1 for these species. No phylogenetic information was available. Therefore we rebuilt the BRT model, still using the data for species introduced to California and Florida but without the variables "AV" and "NN." We chose the best model and used it to make predictions of establishment probability for the species in the independent data set by means of the gbm.predict.grids function (appendix S3 [supporting information] in Elith et al. [2008]). We used deviance explained and AUC as above to evaluate predictive performance. We also correlated predicted probabilities with actual establishment success.

\section{Alternate Predictive Models}

Although the BRT model can be used to make predictions in other geographic areas, its use requires all the data used to build the original model and data for new species to be rerun for every assessment, and that the analyst has training in biology and statistics, including use of the $\mathrm{R}$ programming language. For these reasons, use of BRT by many managers of trade and biosecurity is impractical. We used the results from the BRT model to construct a spreadsheet that can be used to calculate an establishment-probability score (1, extremely low probability; 10 , extremely high probability). To determine these probabilities, the spreadsheet asks a series of questions. Answers to the questions are automatically scaled by formulas in the spreadsheet to a value between 1 and 10 and then weighted according to the contribution of variables in the BRT model. Scaling is based on the shape of the fitted function in the BRT model. We tested the spreadsheet's performance by applying it to the 158 species used in this study (number does not include species in the validation data set) and assessing the correlation between the calculations from the spreadsheet and (1) probabilities of establishment calculated by the BRT and (2) establishment success. A template of the spreadsheet as well as instructions for its use are provided in Supporting Information, but we provide a brief explanation here.

To use the spreadsheet, data to answer all the questions must be collected. However, if phylogenetic data are not available, an alternate model (route 2) can be used. As answers are entered the data are scaled (weighted) automatically by a lookup function. Once all values have been assigned, the final score can be read from the total row. A table is used to convert the total score into a probability of establishment category (6-point scale from extremely low to extremely high). These categories are based on the percentage of species used in testing that established and failed per score (from 1 to 10). The results obtained from applying the spreadsheet to the 158 taxa included in this study are provided in Supporting Information.

\section{Results}

The number of times a species was introduced was by far the variable most strongly associated with establishment success for all of the best BRT models, and age at sexual maturity was the reproductive trait most 

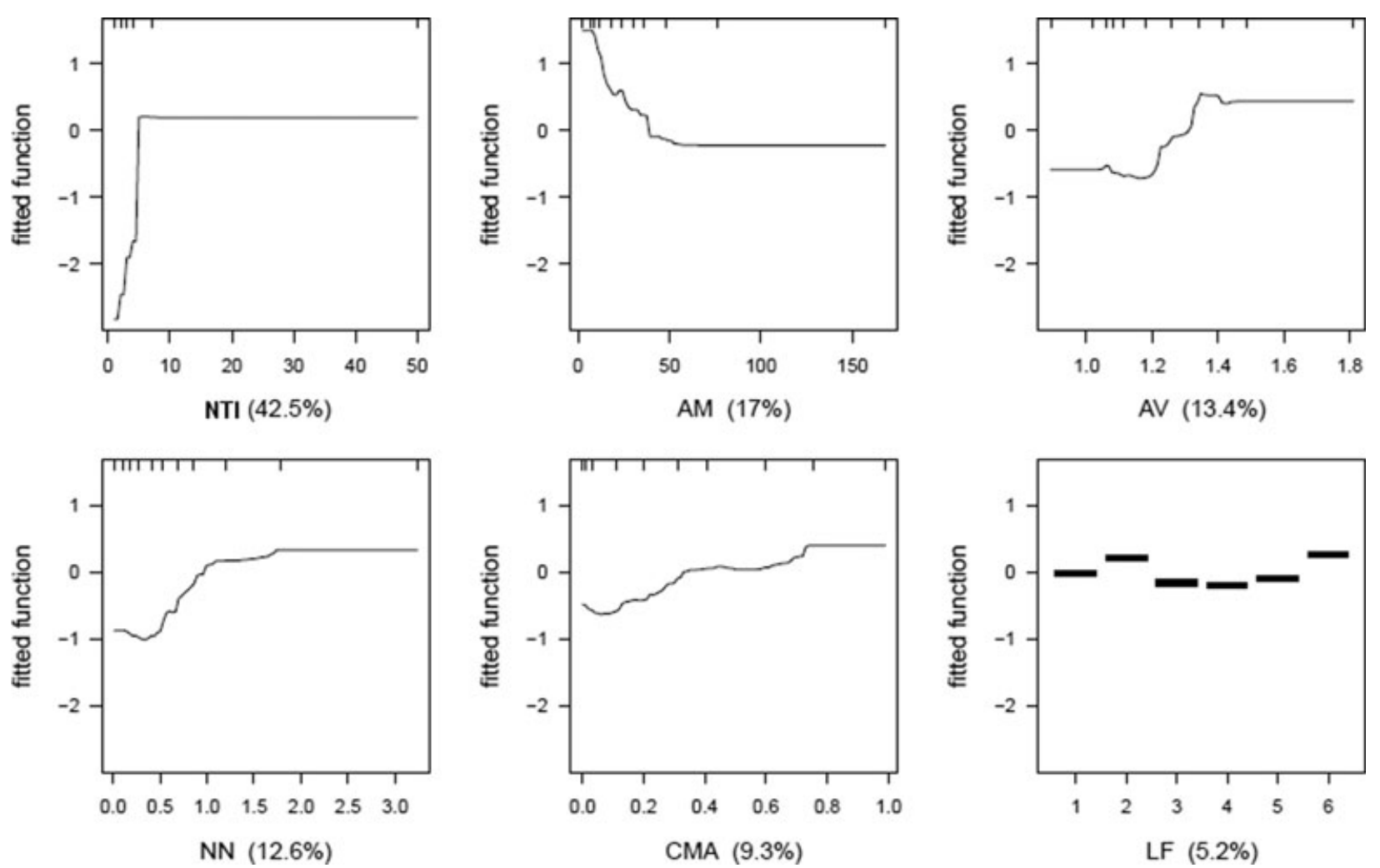

Figure 1. Dependence of the model on each of the six most dominant variables (NTI, number of times introduced; $A M$, age at sexual maturity; $A V$, average phylogenetic distance to all native relatives in the same class; $N N$ phylogenetic distance to the most closely related native species; CMA, average climatic suitability; LF, life form). The relative contribution of each variable to the model is in parentheses. More detailed information on each variable is available in Table 1.

strongly associated with establishment success (Fig. 1 \& Table 2). Species with longer juvenile periods were less likely to establish than those that attained sexual maturity within two years. The two measures of phylogenetic distance-average distance to all native species and distance to the closest native relative-had similar and strong associations with probability of establishment. Average climate match was also important but less so than the number of times introduced, age at maturity, and phylogenetic relatedness (Fig. 1 \& Table 2). Life form of species, used here in place of taxonomic order (crocodile, lizard, snake, turtle, salamander, or frog), also contributed to the establishment success of species in combination with other variables. We used life form and not taxonomic group so as to separate snakes and lizards, which together form a monophyletic group, but have different trade drivers and ecologies that differentially affect their probability of establishment and spread. Frogs $(52.6 \%, n=19)$ and lizards $(50 \%, n=74)$ were the most likely to establish, whereas snakes $(14.3 \%, n=28)$ and turtles $(17.2 \%, n=29)$ were much less likely to establish (Fig. 2). Neither clutch size, number of clutches, nor number of reproductive events a species has per year was selected in the top model.
The best model (estimated from cross validation) explained nearly one-third (29.4\% [SE 0.9]) of the null deviance (Table 2). In addition, the fitted probabilities generated by the model were strongly correlated with establishment success and discriminated well between species that established and those that did not $(r=0.78$, $p<0.001$; Fig. 3a). Use of a threshold probability of 0.39 optimized the balance between false negatives (11 established species had predicted probabilities $\leq 0.39)$ and false positives (10 failed species had predicted probabilities $>0.39$ ) and resulted in an overall error rate of $13.3 \%$. A threshold of 0.5 also resulted in a $13 \%$ error rate, but the distribution of errors was uneven ( 5 false positives and 17 false negatives).

Performance of models was far better when introduction effort (NTI) was included than when this predictor was excluded (Table 2). Model performance also decreased when the two phylogenetic variables were excluded. The top model without these variables explained $21 \%$ of the deviance in cross-validation data sets and $10 \%$ of the deviance in the independent data (Table 2). Despite the exclusion of these phylogenetic variables, the probabilities of establishment fitted by the BRT model for the independent data (species introduced to Great 
Table 2. The predictive performance and the relative contribution of each predictor of non-native herpetofauna establishment success to the top boosted regression tree model; the model that performed best without the predictor introduction effort; and the best model including all predictors available in the independent data set (no phylogenetic information). ${ }^{a}$

\begin{tabular}{|c|c|c|c|c|c|c|c|c|}
\hline \multirow[b]{2}{*}{ Model } & \multirow[b]{2}{*}{$\begin{array}{c}\text { Predictor } \\
\text { variable }\end{array}$} & \multirow{2}{*}{$\begin{array}{c}\text { Relative } \\
\text { contribution } \\
\text { of variable to } \\
\text { model (\%) }\end{array}$} & \multicolumn{3}{|c|}{ Deviance explained (\%) } & \multicolumn{3}{|c|}{ Area under the ROC curve } \\
\hline & & & $\begin{array}{c}\text { Cross } \\
\text { validation }(S E)\end{array}$ & $\begin{array}{l}\text { Training } \\
\quad \text { data }\end{array}$ & $\begin{array}{c}\text { Independent } \\
\text { data }\end{array}$ & $\begin{array}{c}\text { Cross } \\
\text { validation (SE) }\end{array}$ & $\begin{array}{l}\text { Training } \\
\quad \text { data }\end{array}$ & $\begin{array}{c}\text { Independent } \\
\text { data }\end{array}$ \\
\hline $\begin{array}{l}\text { Best tc }=5, \mathrm{lr}= \\
0.001, \mathrm{bf}=0.5\end{array}$ & $\begin{array}{l}\text { NTI } \\
\text { AM } \\
\text { AV } \\
\text { NN } \\
\text { CMA } \\
\text { LF }\end{array}$ & $\begin{array}{r}42.5 \\
17.0 \\
13.4 \\
12.6 \\
9.3 \\
5.2\end{array}$ & $29.4(0.9)$ & 50.9 & na & $0.84(0.03)$ & 0.95 & na \\
\hline $\begin{array}{l}\text { Best without NTI } \\
\qquad \begin{array}{l}\text { tc }=5,1 \mathrm{r}=0.001 \\
\text { bf }=0.5\end{array}\end{array}$ & $\begin{array}{l}\text { AV } \\
\text { AM } \\
\text { CMA } \\
\text { LF } \\
\text { RY }\end{array}$ & $\begin{array}{r}30.4 \\
24.5 \\
23.9 \\
12.4 \\
8.8\end{array}$ & $15.5(0.9)$ & 40.0 & na & $0.75(0.04)$ & 0.93 & na \\
\hline
\end{tabular}

a Abbreviations: $t c$, tree complexity; $l r$, learning rate; bf, bag fraction; NTI, number of times introduced; AM, age at maturity; AV, average phylogenetic distance; $N N$, nearest neighbor distance; CMA, average climate match; LF, life form; na, not applicable.

${ }^{b}$ Many species included in the training data were the same as those introduced to regions we used for independent evaluation. The independent data were thus not entirely independent. However, excluding these species led to a very small sample size and in practice it is likely that the establishment potential of species included in model calibration might be evaluated for a new region (due to the prevalence of these species in trade). When these species were excluded, only 5.28\% of the null deviance was explained.

Britain, Hawaii, and Japan) correlated well with actual establishment success $(r=0.46, p<0.001)$, and there was a significant difference in the probabilities of establishment fitted for failed and established species (MannWhitney test, $p<0.001$, Fig. 3b). A threshold probability of 0.30 optimized the balance between false negatives ( 14 species) and false positives (15 species) and the overall error rate was $25 \%$.

Scores from the spreadsheet correlated extremely well with the top BRT model on which they were based, indicating that the spreadsheet-based model was a good representation of the latter $(r=0.85$ for the method

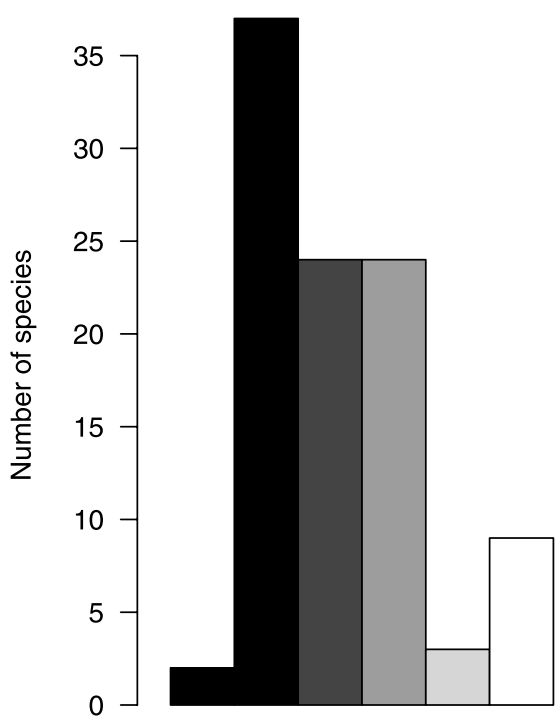

Failed

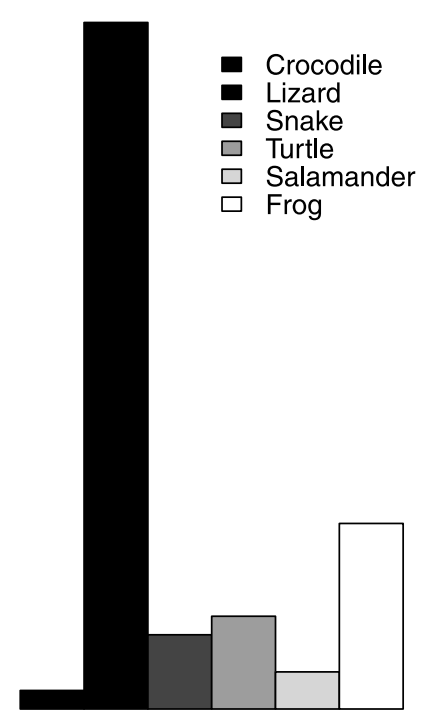

Established
Figure 2. Number of species of non-native reptiles and amphibians that became established and those that failed to establish per life form. 
(a)

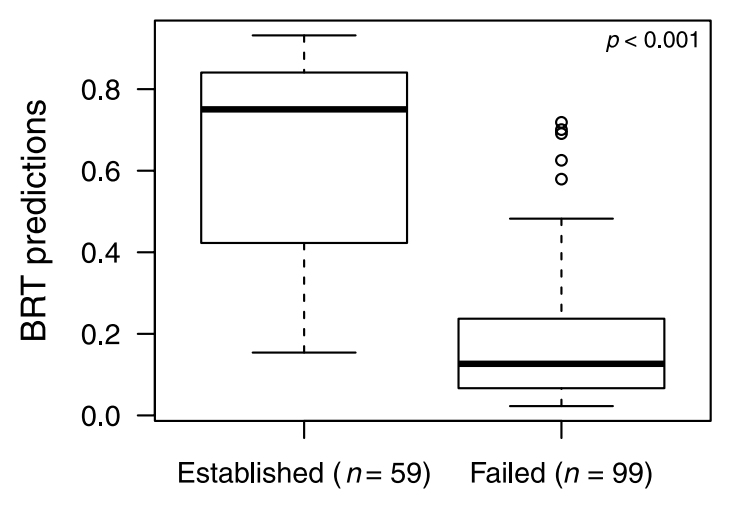

(c)

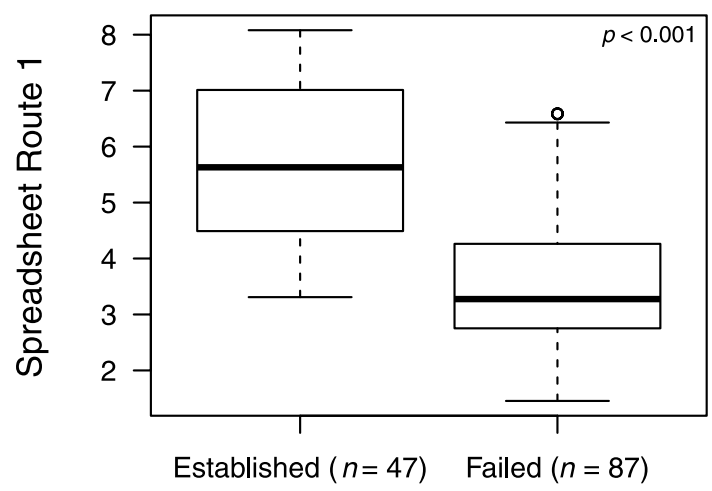

(b)

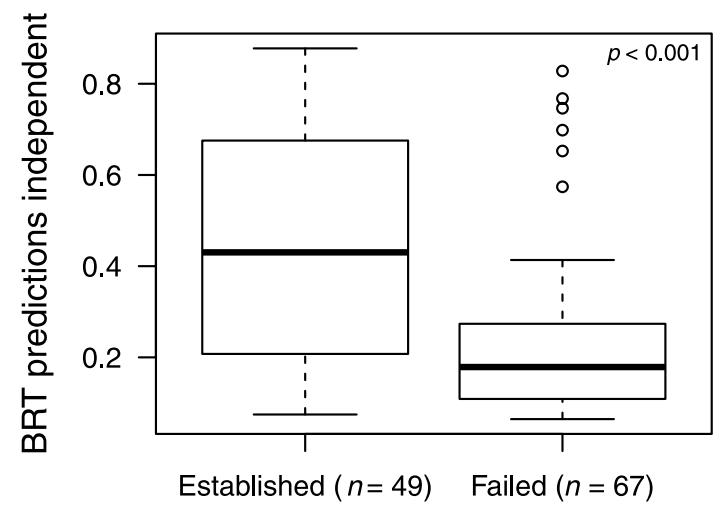

(d)

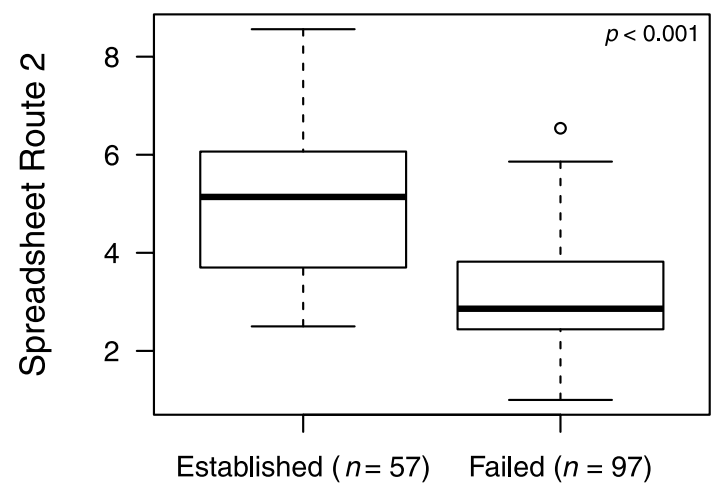

Figure 3. The range of probabilities of establishment success for successful (established) and failed species predicted by (a) the boosted regression tree (BRT) model for non-native species introduced to California and Florida, (b) the revised BRT model for independent data-i.e., species introduced to Britain, Hawaii, and Japan, (c) the spreadsheet model (route 1) for non-native reptiles introduced to California and Florida, and (d) the spreadsheet model (route 2) for reptiles and amphibians introduced to California and Florida (boxes, 25-75\% quantiles; whiskers, points within $1.5 \times$ the interquartile range; open circles, points beyond $1.5 \times$ the interquartile range).

that includes phylogenetic data and $r=0.82$ with route 2 in which taxonomic information is used in place of phylogenetic data, $p<0.001$ ). Furthermore, there was a strong correlation between the scores derived from the spreadsheet and species' establishment success $(r=0.62, p<0.001)$, and the spreadsheet distinguished well between species that failed to establish and those that established $(p<0.001$ for Mann-Whitney; Fig. 3c \& d). Although species with scores $<3$ failed to establish 43 out of 44 times and species with scores $>7$ all established, most species' scores were between 3 and 7 . This made it difficult to choose a threshold score above which species would establish and below which species would fail (Fig. 3 \& Supporting Information). However, when phylogenetic information was used, the balance between false negatives and false positives was optimized at a score of 4.8 ( 16 false negatives and 15 false positives with an overall error rate of $19 \%$ ). When no phylogenetic information was used the optimal score was 4.2 (15 false negatives and 15 false positives with an error rate of $18.3 \%)$.

\section{Discussion}

\section{Predictors of Establishment Success}

When considering whether a species is likely to become established, four groups of variables need to be considered: the introduction effort (Simberloff 2009); the biotic (Strauss et al. 2006; Procheş et al. 2008) and abiotic (Thuiller et al. 2005; Bomford et al. 2009; van Wilgen et al. 2009) characteristics of the new environment; and the life-history traits of the species (Pheloung et al. 1999; Bomford 2003; Meshaka et al. 2004). We tried to account for all these variables by incorporating data on the number of times a species was released, the relatedness of the species to native species already in the region, the suitability of the new climate, and a number of life-history 
Table 3. Comparison of the methods and results of our study with two previous studies that assessed variables associated with reptile and amphibian establishment.

This study

training data, 158 taxa introduced to California and Florida; independent data, 116 taxa introduced to Britain, Hawaii, and Japan

Type of model boosted regression tree

$\begin{array}{cl}\begin{array}{c}\text { Significant } \\ \text { predictors }\end{array} & \text { number of times } \\ & \text { introduced, age at } \\ & \text { maturity, average and } \\ & \text { nearest neighbor } \\ & \text { phylogenetic distance, } \\ & \text { average climate match } \\ & \text { (on basis of six variables), } \\ & \text { and life form (taxonomic } \\ & \text { order) }\end{array}$

Model tested yes
with
independent
data?

Tool suggested for management use of similarly constructed BRT model or spreadsheet tool

Fujisaki et al. 2010

Bomford et al. 2009

model building, 68 reptiles introduced to Florida; predictive risk of future establishment model, 33 reptile species commonly imported into Florida

discriminant analysis, logistic regression, recursive partitioning, regression trees (rpart)

1. Chi-square tests of significance: taxonomic order, juvenile \& adult diet, age at maturity, manageability (maintenance cost, aggressiveness, venomousness, proneness to escape).

2. Discriminant analysis: sale price and manageability. 3. Logistic regression: taxonomic order, manageability.

4. Classification tree: maximum temperature match, manageability.

no, but models applied to assess risk posed by 33 species that are commonly imported into Florida but are not yet established or failed

combination of methods and comparison of results global analysis of individual variables, 1995 taxa introduced anywhere worldwide outside of their native range; detailed analysis, 185 taxa introduced to Britain, California, and Florida

logistic regression (generalized additive mixed model) as well as other models for individual variables

for all non-native introductions (1995 taxa), genus, family, taxonomic order, number of jurisdictions of introduction (surrogate for introduction effort); for species introduced to Britain, California, and Florida, climate match (on the basis of 16 variables), establishment success elsewhere, jurisdiction of introduction no

fitted model used in the paper, but the authors suggest further work traits that predispose species to establishment due to their high reproductive potential.

As reported elsewhere (Duggan et al. 2006; Simberloff 2009), we found that the number of times a species has been introduced (propagule pressure) was the variable most strongly associated with probability of establishment, although information on introduction effort may not be available a priori, which limits its use in predictive models. Our results are also consistent with those of Bomford et al. (2009) and Fujisaki et al. (2010) in that species originating from areas with climates similar to the region of introduction and those that attain sexual maturity at younger ages were more likely to establish than those from less-similar climates or those that reach maturity later (Table 3 ). The latter finding probably accounts for the higher probability of establishment in frogs and lizards, as opposed to turtles and snakes, because turtles and snakes tend to reach maturity later than species in the former two groups. We also found that reptile species that are more distantly related to native species have a higher probability of establishing successful breeding populations than those with closer native relatives.
Although there are a number of possible explanations for this finding (e.g., competitive exclusion and enhanced likelihood of spreading disease between close relatives or novel niche exploitation by species without close relatives), there are unresolved questions about why these variables should operate at the broad spatial scale of this study (van Wilgen \& Richardson 2011). However, we believe the phylogenetic variables still serve as useful predictors of future establishment success because biotic interactions undoubtedly affect species' ability to establish and these variables had strong explanatory power.

Despite progress in identifying variables correlated with establishment success in many taxonomic groups (Lockwood et al. 2007), predicting whether a given species will become established remains extremely challenging. One of the greatest problems is the paucity of data (Fujisaki et al. 2010). Many herpetofaunal species are poorly studied in their natural habitats. Lack of detailed distribution data (in the form of point-locality presences and absences), for example, thwarts attempts to reliably estimate regions of suitable climate (Elith et al. 2006; van Wilgen et al. 2009). Furthermore, although there is an 
extensive literature on certain reproductive traits, such information is not always useful. For instance, herpetologists tend to collect data on the size of a species at first reproduction because this is one of the best predictors of when an individual will first reproduce. However, in examinations of the establishment of non-native species, the mean or median age at which this maturity occurs needs to be determined because species with a tendency to reproduce earlier (within the first two years) are more likely to establish. Despite these challenges, decisions regarding whether to allow trade in species need to be made.

\section{Predicting Establishment}

Boosted regression trees are known to have better discriminatory power than other conventional modeling techniques (Leathwick et al. 2006; Elith et al. 2008). However, BRTs tend to overfit models to training data (Leathwick et al. 2006; Elith et al. 2008). Consequently, low error rates derived from training data must be interpreted with caution. Overfitting may be partly responsible for the poorer performance of our model when we used the independent data set (species introductions to Great Britain, Hawaii, and Japan). However, the deficiency of data for many of the species in the independent data set and exclusion of the two phylogenetic variables may also have contributed to the reduced performance. Where feasible, the best solution is to recreate a BRT model with the most current data and to include as many species as possible. Thus, we included our data in the Supporting Information so that the data can be augmented and the model rerun as new data become available. We also recommend erring on the side of caution when probabilities of establishment are interpreted because false positives (species predicted to establish but would not) are likely to have less of an effect than false negatives (e.g., species that are allowed for import due to a low score and subsequently establish in the wild). Using a threshold probability of $<0.39$ reduces the number of false negatives (see Results).

The spreadsheet we designed is a simpler technique than the BRT model. When using the spreadsheet, it is important that information to answer all the questions be obtained. This is not always a simple task, but options are available to obtain information for each of the variables included in the model. Propagule pressure is difficult to estimate a priori, but we recommend some estimate of introduction effort be incorporated into models. The sale price and manageability of a species have been used to determine the number of individuals likely to be traded and or released from captivity (Fujisaki et al. 2010; van Wilgen et al. 2010). Species that are unmanageable or are prevalent in the pet trade should thus be assigned high scores for propagule pressure. In the absence of data, one may also score estimates of this variable higher as a precautionary measure.

Obtaining an estimate of climatic similarity is also difficult. Ideally, one would create a niche model or obtain the results of such a model from a previous study. Outputs of the niche models we used in this study are available in the Supporting Information and in van Wilgen et al. (2009). If creating a niche model is not feasible, a function on the GBIF website (http://data.gbif.org/welcome.htm) allows one to create a niche model online. Before using this function, it is advisable to inspect the quantity and quality of data that the model will be based on and to choose only the most relevant climatic variables to include (van Wilgen et al. 2009). Phylogenetic information is not readily available in the format required for use of the spreadsheet. We therefore introduced a second option (route 2) with which taxonomic order of the closest relative is used in place of the phylogenetic information. Finally, life-history data are notoriously difficult to obtain for herpetofauna. Data from breeders and the pet trade are of some use in this regard, but do not compensate for data from free-living populations. A challenge in this field is deciding how best to incorporate data from captive animals without generating spurious results. Although the BRT model can be run with some missing data, we suggest that the spreadsheet estimates of life-history traits be made on the basis of traits of related taxa.

If one is concerned about the quality of data used as model input, one could use other models that require different data that may be more readily available. Fujisaki et al. (2010) suggest that multiple models be used and compared. In Table 3, we outline the factors from our study as well as those of Bomford et al. (2009) and Fujisaki et al. (2010) that influence reptile and amphibian establishment and the models and sample sizes on which these inferences have been made. Including additional models, such as those from the studies in Table 3, to explain establishment success may provide extra evidence on which to base decisions. We do, however, recommend that caution be exercised with the invasive-elsewhere variable. This predictor largely provides an indication of prevalence in introduction pathways rather than of a species' inherent potential to establish. Most herpetofaunal introductions have been too recent for the invasiveelsewhere factor to be of much use. Many non-native pet species are introduced to multiple areas, but either low propagule pressure has prevented establishment or insufficient time has passed to detect emerging populations.

\section{Caveats and Implications for Biosecurity}

Much of the data available on failed herpetofaunal introductions is on species that were likely not given a realistic opportunity to establish (e.g., a few individuals were released only one time). Comparing such introductions with those in which a species was introduced in 
large numbers, multiple times is biased. There is however little that can be done about this if adequate sample sizes for modeling are to be obtained. Another problem is phylogenetic nonindependence (Felsenstein 1985). The true sample size (in this and previous studies) may be limited even further if accounting for nonindependence of related species is deemed necessary. The fact that so many invasive species come from the same families and orders emphasizes that these groups may simply be more adept at establishing and spreading or be more prevalent in introduction pathways than others. For herpetofauna the following families have had a disproportionate number of non-native species become established: Emydidae (freshwater turtles), Bufonidae (toads), Ranidae (frogs), Gekkonidae (geckos), and Polychrotidae (anoles). Many of the established non-native species from these families are common in the pet trade, which increases their propagule pressure. However, there may be some other characteristics shared by these groups that add to their establishment success.

Although lack of data still limits the ability of models to make predictions, there are some factors that consistently increase the probability of species establishment. We recommend that when using models to make predictions, the outputs should not be considered as precise probabilities of establishment, but rather as an indication of the probability of establishment relative to other species. In general, species (especially lizards and frogs) that mature early and come from similar environments to that of a region of potential introduction are likely to establish and should probably not be allowed, irrespective of other factors.

\section{Acknowledgments}

We thank G. Hood, F. Ficetola, and two anonymous reviewers for comments on the manuscript, J. Elith for insightful comments on the use of BRTs and evaluating their predictive power, and $\mathrm{M}$. Bomford for discussion on reptile risk assessment. Financial support for this work came from the Australian Centre of Excellence for Risk Analysis, the Department of Science and Technology National Research Foundation Centre of Excellence for Invasion Biology, the Wilhelm Frank Bursary Fund (N.v.W.), Cape Action for People and the Environment, and the Hans Sigrist Foundation (D.M.R.).

\section{Supporting Information}

An Excel workbook (Appendix S1) containing the list of species and the data used in the initial BRT model and the independent data set; an Excel spreadsheet model for predicting relative establishment probability of introduced reptiles and amphibians (Appendix S2); and 24 high-resolution maps of the predicted worldwide cli- matic suitability for 72 species, including an Excel key to the maps (Appendix S3) are available on-line. The authors are solely responsible for the content and functionality of these materials. Queries (other than absence of the material) should be directed to the corresponding author.

\section{Literature Cited}

Andersen, M. C., H. Adams, B. Hope, and M. Powell. 2004. Risk assessment for invasive species. Risk Analysis 24:787-793.

Auliya, M. 2003. Hot trade in cool creatures: A review of the live reptile trade in the European Union in the 1990's with a focus on Germany. TRAFFIC Europe, Brussels.

Beard, K. H., and W. C. Pitt. 2005. Potential consequences of the coqui frog invasion in Hawaii. Diversity and Distributions 11:427-433.

Bomford, M. 2003. Risk assessment for the import and keeping of exotic vertebrates in Australia. Australian Government: Department of Agriculture, Fisheries \& Forestry, Canberra.

Bomford, M., F. Kraus, S. C. Barry, and E. Lawrence. 2009. Predicting establishment success for alien reptiles and amphibians: a role for climate matching. Biological Invasions 11:713-724.

Bomford, M., F. Kraus, M. Braysher, L. Walter, and L. Brown. 2005. Risk assessment model for the import and keeping of exotic reptiles and amphibians. Australian Government Bureau of Rural Sciences, Canberra.

Burgman, M. 2005. Risks and decisions for conservation and environmental management. Cambridge University Press, Cambridge, United Kingdom.

Duggan, I. C., C. A. M. Rixon, and H. J. MacIsaac. 2006. Popularity and propagule pressure: determinants of introduction and establishment of aquarium fish. Biological Invasions 8:377-382.

Elith, J., et al. 2006. Novel methods improve prediction of species' distributions from occurrence data. Ecography 29:129-151.

Elith, J., J. R. Leathwick, and T. Hastie. 2008. A working guide to boosted regression trees. Journal of Animal Ecology 77:802-813.

Felsenstein, J. 1985. Phylogenies and the comparative method. The American Naturalist 125:1-15.

Ferrier, S., and G. Watson. 1997. An evaluation of the effectiveness of environmental surrogates and modelling techniques in predicting the distribution of biological diversity. Consultancy report to the Biodiversity Convention and Strategy section of the Biodiversity Group, Environment Australia. New South Wales National Parks and Wildlife Service, Environment Australia, Sydney.

Ficetola, G. F., W. Thuiller, and E. Padoa-Schioppa. 2009. From introduction to the establishment of alien species: bioclimatic differences between presence and reproduction localities in the slider turtle. Diversity and Distributions 15:108-116.

Forsyth, D. M., R. P. Duncan, M. Bomford, and G. Moore. 2004. Climatic suitability, life-history traits, introduction effort, and the establishment and spread of introduced mammals in Australia. Conservation Biology 18:557-569.

Fujisaki, I., K. M. Hart, F. J. Mazzotti, K. G. Rice, S. Snow, and M. Rochford. 2010. Risk assessment of potential invasiveness of exotic reptiles imported to south Florida. Biological Invasions 12:2585-2596

Grosholz, E. 2002. Ecological and evolutionary consequences of coastal invasions. Trends in Ecology \& Evolution 17:22-27.

Hanley, J. A., and B. J. McNeil. 1982. The meaning and use of the area under a receiver operating characteristic (ROC) curve. Radiology 143:29-36.

Hulme, P. E. 2011. Biosecurity: the changing face of invasion biology Pages 301-314 in D. M. Richardson, editor. Fifty years of invasion ecology. The legacy of Charles Elton. Wiley-Blackwell, Oxford, United Kingdom. 
Kraus, F. 2003. Invasion pathways for terrestrial vertebrates. Pages 292-349 in G. Ruiz and J. Carlton, editors. Invasive species: vectors and management strategies. Island Press, Washington, D.C.

Kraus, F. 2009. Alien reptiles and amphibians: a scientific compendium and analysis. Springer, Dordrecht, The Netherlands.

Leathwick, J. R., J. Elith, M. P. Francis, T. Hastie, and P. Taylor. 2006. Variation in demersal fish species richness in the oceans surrounding New Zealand: an analysis using boosted regression trees. Marine Ecology Progress Series 321:267-281.

Lockwood, J. L., M. F. Hoopes, and M. P. Marchetti. 2007. Invasion ecology. Blackwell Publishing, Oxford, United Kingdom.

Mack, R. N., D. Simberloff, W. M. Lonsdale, H. Evans, M. Clout, and F. A. Bazzaz. 2000. Biotic invasions: causes, epidemiology, global consequences, and control. Ecological Applications 10:689-710.

Meshaka, W. E. J., B. P. Butterfield, and J. B. Hauge. 2004. The exotic amphibians and reptiles of Florida. Krieger Publishing, Malabar, Florida.

Pheloung, P. C., P. A. Williams, and S. R. Halloy. 1999. A weed risk assessment model for use as a biosecurity tool evaluating plant introductions. Journal of Environmental Management 57:239251.

Procheş, Ş., J. R. U. Wilson, D. M. Richardson, and M. Rejmánek. 2008. Searching for phylogenetic pattern in biological invasions. Global Ecology and Biogeography 17:5-10.

R Development Core Team. 2011. R: a language and environment for statistical computing. R Foundation for Statistical Computing, Vienna.

Reed, R. N. 2005. An ecological risk assessment of nonnative boas and pythons as potentially invasive species in the United States. Risk Analysis 25:753-766.

Richardson, D. M., P. Pyšek, and J. T. Carlton. 2011. A compendium of essential concepts and terminology in invasion ecology. Pages 409-420 in D. M. Richardson, editor. Fifty years of invasion ecology: the legacy of Charles Elton. John Wiley \& Sons, West Sussex, United Kingdom.

Richardson, D. M., P. Pyšek, M. Rejmánek, M. G. Barbour, F. D. Panetta, and C. J. West. 2000. Naturalization and invasion of alien plants: concepts and definitions. Diversity and Distributions 6:93-107.
Ridgeway, G. 2007. Generalized boosted regression models. Documentation on the $\mathrm{R}$ Package 'gbm' version 1.6-3. Available from http://cran.r-project.org/web/packages/gbm/gbm.pdf (accessed October 2009).

Rodda, G. H., C. S. Jarnevich, and R. N. Reed. 2009. What parts of the US mainland are climatically suitable for invasive alien pythons spreading from Everglades National Park? Biological Invasions 11:241-252.

Rödder, D. 2009. Human Footprint, facilitated jump dispersal, and the potential distribution of the invasive Eleutberodactylus jobnstonei Barbour 1914 (Anura Eleutherodactylidae). Tropical Zoology 22:205-217.

Simberloff, D. 2009. The role of propagule pressure in biological invasions. Annual Review of Ecology, Evolution and Systematics 40:81-102.

Strauss, S.Y., C. O. Webb, and N. Salamin. 2006. Exotic taxa less related to native species are more invasive. Proceedings of the National Academy of Sciences of the USA 103:5841-5845.

Thuiller, W., D. M. Richardson, P. Pyšek, G. F. Midgley, G. O. Hughes, and M. Rouget. 2005. Niche-based modelling as a tool for predicting the risk of alien plant invasions at a global scale. Global Change Biology 11:2234-2250.

van Wilgen, N. J., J. Elith, J. R. Wilson, B. A. Wintle, and D. M. Richardson. 2010. Alien invaders and reptile traders: What drives the live animal trade in South Africa? Animal Conservation 13(supplement 1):24-32.

van Wilgen, N. J., and D. M. Richardson. 2011. Is phylogenetic relatedness to native species important for the establishment of reptiles introduced to California and Florida? Diversity and Distributions 17:172-181.

van Wilgen, N. J., N. Roura-Pascual, and D. M. Richardson. 2009. A quantitative climate-match score for risk-assessment screening of reptile \& amphibian introductions. Environmental Management 44:590-607.

WWF-US (World Wildlife Fund-United States). 2006. WildFinder. Version Jan-06. WWF-US, Washington, D.C. Available from http://gis.wwfus.org/wildfinder/ (accessed January 2008).

Yee, T. W., and N. D. Mitchell. 1991. Generalised additive models in plant ecology. Journal of Vegetation Science 2:587-602.

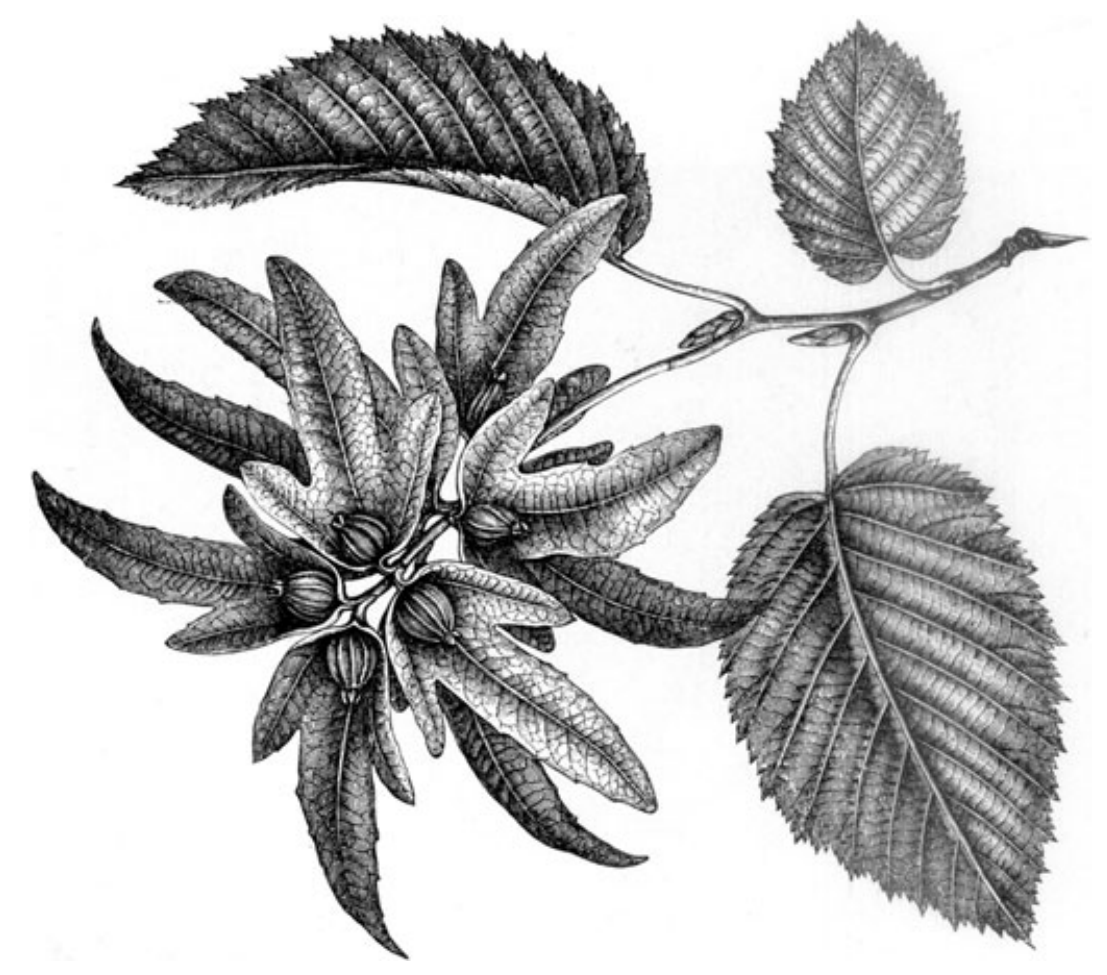

